\title{
A DEMOCRACIA E O PENSAR HUMANO: REFLEXÕES PEDAGÓGICO-EDUCACIONAIS EM AMARTYA SEN E HANNAH ARENDT $^{1}$
}

\author{
DEMOCRACY AND HUMAN THINKING: PEDAGOGICAL AND EDUCATIONAL \\ REFLECTIONS IN AMARTYA SEN AND HANNAH ARENDT
}

\section{Claudeonor Antônio de Vargas}

Universidade de Passo Fundo, RS, Brasil. E-mail: vargasclaudeonorvargas@gmail.com

\author{
Jenerton Arlan Schütz \\ Universidade Regional do Noroeste do Estado do Rio Grande do Sul, Ijuí, RS, Brasil. E-mail: \\ jenerton.xitz@hotmail.com
}

DOI: https://doi.org/10.46550/amormundi.v1i2.22

Recebido em: 14.09.2020

Aceito em: 24.11.2020

\begin{abstract}
Resumo: O presente ensaio contém um recorte pontual das elaboraçóes teóricas de dois autores situados em âmbitos distintos. Amartya Sen desenvolve suas reflexôes a partir da Economia e expressa os ensinamentos imbricados com a democracia e seu potencial interno de constituição e estruturação das relaçóes entre a singularidade e a pluralidade, entre o eu e o nós. Hannah Arendt mostra o seu potencial intelectual com base na Filosofia e contempla as características e a necessidade do pensar por si mesmo na relação direta com a formação pedagógico-educacional a partir de sua visão de atuação docente que envolve situar o sujeito singular entre outros. À parte final do ensaio compete problematizar as profundas imbricaçôes e possibilidades relacionadas a um sistema de governo democrático com a ideia de formação de um sujeito capaz de, a partir de si mesmo, apreender a realidade e intervir na mesma.
\end{abstract}

Palavras-chaves: Democracia. Cidadania. Pensar. Educação.

\begin{abstract}
The present essay contains a specific section of the theoretical elaborations of two authors located in different areas. Amartya Sen develops her reflections from the Economy and expresses the teachings imbricated with democracy and its internal potential for constituting and structuring the relations between singularity and plurality, between self and us. Hannah Arendt shows her intellectual potential based on Philosophy and contemplates the characteristics and the need to think for herself in the direct relationship with the pedagogicaleducational formation from her view of teaching performance that involves situating the singular subject among others. The final part of the essay is concerned with problematizing the profound imbrications and possibilities related to a system of democratic government with the idea of forming a subject capable of, starting from himself, apprehending reality and intervening in it.
\end{abstract}

Keywords: Democracy. Citizenship. Think. Education.

1 Utilizaremos, neste ensaio, algumas obras em Espanhol; a responsabilidade da tradução é nossa. 


\section{Introduçáo}

Vivemos tempos de mudanças exponenciais e complexificadoras das relaçóes humanas. Uma das mais contundentes é a de que os sujeitos em interação não mais aceitam, passivamente, as determinaçôes e comandos estruturados em uma ótica autoritária. Ao contrário, reagem frente às imposições unilaterais, percebidas como desrespeitosas e castradoras do ser singular. A questáo que emerge desta postura frente às divergências existenciais surgidas no âmbito de uma sociedade plural e movediça em termos de visão de mundo é a de como efetivar este posicionamento. E também de como o mesmo pode dar-se sob o estatuto da liberdade individual expressada em meio à vida coletiva. Neste sentido, o presente ensaio intenta percorrer os meandros da ideia de liberdade contida no conceito de democracia e da concepção do pensar por si mesmo como elementos possibilitadores da constituição de um sujeito apto a enfrentar as vicissitudes da vida. O elemento de fundo desta problemática é a reflexão acerca das açôes no universo pedagógico-educacional norteada pela ideia de formaçáo humana integral, ou seja, para além da instrumentalização técnica.

Para dar curso às pretensóes acima descritas trabalharemos com referencial bibliográfico dentro da perspectiva da hermenêutica de Gadamer ${ }^{2}$, guiados pelo conceito de adequado em contraposição ao de medido. Por medido, entende-se tudo que pode ser observado experimentado e comprovado -, excluindo-se tudo o que náo atenda a estas exigências. Por adequado, compreende-se algo que náo pode ser verificado e que se situa no âmbito do aporético, do não finalizado. Isto exige do pesquisador um triplo movimento a) o acesso ao texto, na forma como ele se apresenta, b) o distanciamento necessário do mesmo e c) o retorno a si próprio, agora com as modificações inerentes ao estranhamento realizado.

Com base nesta metodologia apresentaremos, na primeira parte, as elaboraçóes teóricas de Amartya Sen acerca da democracia como paradigma impulsionador do desenvolvimento fundado em açóes humanas centradas no respeito ao singular e no comprometimento com o plural. Na segunda, adentraremos no desenvolvimento filosófico de Hannah Arendt sobre o pensar e de suas imbricaçóes relacionadas à postura docente. Encerraremos com o exercício aporético de refletir sobre ambas as teorizaçôes e de suas imbricaçôes e possibilidades no universo da educação formal.

\section{Amartya Sen e a democracia}

Três fatores nos conduziram a tratar da questão da democracia a partir do pensamento de Sen, escritor e economista indiano, laureado com o Prêmio de Ciências Econômicas de 1998, inspirado em $\mathrm{Nobel}^{3}$. Primeiro, a influência de Martha Nussbaum, filósofa contemporânea, que o cita com frequência, deixando entrever sua admiração e apreço pelas ideias de Sen. Segundo, Sen vincula à questão do desenvolvimento de um país a capacidade deste de oferecer à população espaço e oportunidade de fazer escolhas fundadas no conceito de cidadania. Neste sentido, a democracia representa o impulso à livre expressão das necessidades e aspiraçóes fundamentais ao ser humano civilizado. Dentre estas, apresentam-se como vitais a garantia dos direitos sociais,

2 GADAMER, Hans-Georg. O caráter Oculto da saúde, 2006, p. 130-144.

3 Evidentemente que reconhecemos o valor dos escritos de Sen por si só, porém, confessamos termos sidos "picados pelo moscardo socrático" a partir das citações constantes em algumas obras de Martha Nussbaum. 
como a segurança, a saúde e a educação, e a geração de condiçóes para o exercício da liberdade socialmente construida em um mundo que assiste à escalada crescente da complexidade e da diversidade cultural, ideológica e teológica. Terceiro, por encontrar-se nesta ideia de construção social das condiçóes do conviver o elemento para refletir acerca da capacidade humana do pensar, o que nos levará, na segunda parte deste trabalho, à filósofa alemã Hannah Arendt. Por hora, vejamos como Sen defende a tese da democracia como valor universal e como define as funçôes da democracia para, a partir destas compreensóes, evidenciarmos a exigência posta nas entrelinhas acerca do pensar humano e de como isso aporta contribuiçóes para refletir sobre a educação contemporânea.

\subsection{Democracia ${ }^{4}$ como um valor universal}

Amartya Sen, em resposta a uma pergunta a ele dirigida em determinado momento, acerca de qual entenderia ser o acontecimento mais importante do século XX, mesmo considerando os eventos transcorridos nos últimos cem anos - fim dos impérios europeus da França e da Inglaterra, guerras mundiais, ascensão e queda do fascismo, do nazismo e do comunismo, entre tantos outros -, responde convictamente ser:

[...] a ascensão da democracia. Isto não implica que outros acontecimentos sejam menos importantes, porém creio que no futuro, quando olharmos para trás buscando entender o que se passou ao largo deste século, não haverá dúvidas em aceitar a supremacia da emergência da democracia, que terá constituído, de maneira muito notável, a única forma aceitável de governo (SEN, 2006, p. 56, grifo nosso).

Neste sentido, podemos depreender da afirmação do autor que, junto com a definição de democracia como a única forma aceitável de governo, advém uma concepção de sociedade que lhe é inerente, em um duplo aspecto. No primeiro, negativo, trata-se de rechaçar todas as formas autoritárias de relação, em suas mais diversas dimensôes e particularidades. Isto vale para as antigas e ultrapassadas visóes relacionais amparadas na aristocracia, na teologia e no patriarcalismo. Rechaço que se estende também sobre formas de subjugação mais sutis como as derivadas do poder econômico, político, religioso e cultural, em frequente associação com uma mídia corporativa bem remunerada que busca realizá-las ao mesmo tempo em que se locupleta e lhes dá sustentação. Enfim, exige a negação da instauração e da utilização do poder de maneira unilateral e sem a consequente concordância dos que serão a ele submetidos, em uma subversão absoluta da ideia de autoridade consentida. No segundo, positivo, a perspectiva é a de fomento às articulaçôes que intentem dotar as relaçóes sociais da inclusão do outro, seja nos termos práticos da existência concreta, seja na dimensão subjetiva das ideias e aspiraçóes singulares. Neste sentido, mesmo nas instituiçóes sociais em que a prerrogativa abstrata da autoridade assume forma concreta em um alguém específico, em que o poder oriundo daquela é exercido por este, a origem e a configuração devem primar pelo respeito aos direitos de outrem. Em

4 A ideia de democracia, como nós a conhecemos no Ocidente, remonta a Grécia de dois mil anos atrás, evidentemente que cercada das idiossincrasias da época e de suas limitaçôes diante da estruturação das sociedades de então. A evolução desta ideia de democracia, ao longo da existência humana, envolve avanços e retrocessos localizados no tempo e no espaço geográfico de determinadas naçốes, em algumas situaçôes imbricadas entre si por questôes de ordem econômica e/ou políticas. Não é nossa intenção, neste ensaio, nem teríamos hoje o alcance teórico necessário, para nos alongarmos no desvelamento da gênese, do desenvolvimento e da possibilidade de constituição da democracia como sistema de governo. 
suma, a autoridade exercida precisa estar em consonância com a ideia de autoridade validada, compartilhada e consentida pelos pares em interação. A concepção de sociedade resultante, nestes termos, emerge da soma simultânea da negação do autoritarismo com a franquia da constituição social de autoridade fundada no reconhecimento de capacidades levadas a termo de forma condizente com as situações vivenciadas. Pensamos que é a partir desta visão de mundo que se tornou possível a mudança apontada pelo autor:

Ao largo do século XIX [...] teóricos da democracia [...] se perguntavam acerca de se tal ou qual país estava realmente "preparado para a democracia". Dito pensamento não mudou até o século XX [...] um país não tem que considerarse adequado ou preparado para a democracia; em lugar disto, tem que voltar-se adequado mediante a democracia (SEN, 2006, p. 58, grifo nosso).

O "voltar-se adequado para a democracia" contém, neste sentido, o germe proporcionador de alteraçóes profundas nas formas de relaçôes sociais. Muito provavelmente foi assim que, ao largo do século XX, as pessoas maiores de idade adquiriram o direito ao voto (inclusive mulheres e analfabetos), o direito à saúde e o acesso à Escola tomaram ares de universalidade e a questão da vida adquiriu status de prioridade absoluta.

\subsection{Democracia e suas múltiplas funçóes}

Que é, exatamente, a democracia? Para começar, devemos evitar sua identificação com a ideia de governo da maioria. [...] A democracia é um sistema exigente e não só uma condiçấo mecânica (como a referida ao governo da maioria) tomada de forma separada (SEN, 2006, p. 72).

Do acima expressado surge a ideia de sistema orgânico, com níveis de flexibilidade e com espaços para alteraçóes originadas a partir das demandas sociais. Sistema que explicita a atuação concomitante da reverberação das necessidades e aspiraçóes dos cidadãos com o atendimento das normas e regras instituídas no âmbito público da representatividade política. Sen destaca três virtudes do sistema democrático que, além de reforçar a tese de valor universal da democracia, permite que a mesma torne a vida dos cidadãos mais rica. Na primeira, a democracia percebe a Liberdade Política como sendo parte integrante da liberdade em geral e possuindo valor intrínseco para a vida e o bem-estar humano. No sentido aqui apregoado, "o exercício dos direitos civis e políticos resulta crucial para a boa vida dos indivíduos entendidos como seres sociais" (SEN, 2006, p.73), ou seja, exercer a cidadania em sua face ativa oferta a perspectiva de uma vida bem vivida. Na segunda, a democracia possui Valor Instrumental no sentido de que dispóe, reforça e exige a atenção dos governantes para as demandas dos cidadãos "incluindo reinvindicações e necessidades econômicas" (SEN, 2006, p. 74). Aqui tais clamores apresentam-se em caráter necessário, sejam eles coletivos ou oriundos de projetos pessoais. Por fim, a democracia implica a Construção Social de Valores, com a experiência de aprender uns com os outros e a característica de "ajudar a sociedade a formar seus valores e estabelecer suas prioridades" (SEN, 2006, p. 74). $\mathrm{O}$ aspecto relevante desta função é o de elaboração coletiva da normatividade interacional que implica a busca de entendimento mútuo e o respeito à mesma em sua operacionalidade. 


\subsection{Democracia e uma exigência fundamental: a capacidade para pensar}

Do conjunto das três virtudes destacadas por Sen acima arroladas, brota o elemento que irá nos direcionar para a questáo do pensar humano. Na primeira há a evidente necessidade de refletir sobre "direitos civis e políticos", na segunda o mesmo dá-se para a elaboração de "reinvindicações e necessidades econômicas" e, fechando o ciclo definido pelo autor, "formar valores e definir prioridades" põe a mesma exigência. Pensamos que esta complexa gama de temas - liberdade, necessidades econômicas, direitos civis e políticos, discussão pública, formação de valores, definição de prioridades, etc. -, não se manifesta pura e simplesmente por conta de uma “autorização" externa. É necessário, evidentemente, que o sistema de governo vigente permita que os seus cidadãos tenham liberdade de elaboração existencial em nível público, porém, isto por si só não é suficiente. O que seria suficiente então? Qual o elemento que possibilitaria avaliar prós e contras de determinadas situaçóes? O que proporcionaria as condiçóes adequadas para que o cidadão, primeiro, perceba-se como tal, e, segundo, assuma uma postura ativa em termos de vivência efetiva desta cidadania? E qual o vínculo deste elemento com a educação formal? Pensamos que uma condição prioritária, se não talvez a principal, seja a capacidade para pensar. Mas o que isto significa, de fato? Quais as características que se apresentam a esta faculdade? Qual a perspectiva de resoluções práticas relacionadas a esta dimensão? Sob que visão pedagógica a faculdade de pensar encontra maiores condiçóes de germinar? Veremos isto a seguir, a partir de Hannah Arendt, partindo da forma com que ela se aproxima das atividades do espírito, descrevendo a sua postura docente e trabalhando o seu desenvolvimento teórico referente ao pensar.

\section{Hannah Arendt e o pensar}

O interesse de Arendt pelas denominadas atividades do espirito, entre as quais o pensar adquire um status relevante, é algo que marca suas reflexôes na década de 1970. No dizer de Almeida, tais atividades são "exercidas ao se estar só e invisíveis aos olhos do mundo, isto é, atividades claramente distintas da ação no plural e das experiências no espaço público" (2011, p. 149). Isto é, são atividades individuais, singulares, não visíveis aos demais, levadas a termo em espaço privado e que contém em seu sentido último uma exigência primordial: a retirada do mundo "que está presente para os sentidos" (ARENDT, 1991, p. 60). Resta importante, para os nossos fins, destacar que Arendt envolve-se com as atividades do espírito quando enviada pela revista New Yorker para cobrir o julgamento de Eichmann ${ }^{6}$ em Jerusalém. Infere-se desta ocorrência que a conjunção de um evento de interesse internacional (Eichmann é levado a julgamento por crimes de guerra contra os judeus e, em primeira instância, contra a humanidade) com o interesse pessoal (Arendt é de origem judia) mediado pelo potencial intelectual de Arendt, resulta prolífica à produção do conhecimento. Compreendemos este episódio como exemplar para dotar a capacidade do pensar humano do estatuto de relevância determinante da condição

5 Em Arendt, estar só difere de solidão. Esta ocorre quando o sujeito se encontra em um estado existencial em que ele próprio ausenta-se de si mesmo, em uma dupla privaçáo que inviabiliza o ser singular do sujeito. Aquela implica em uma dualidade da consciência, em um conhecer consigo mesmo como condição à vida própria do espírito (Arendt, 1991, p. 58-59).

6 As questôes de fundo desta experiência empírica que conduziram Arendt a tecer seu conceito acerca da banalidade do mal e do pensar humano não serão aqui tratadas. Tais questóes e desenvolvimentos podem ser encontrados, inicialmente, conforme indica a própria autora, na obra $A$ condição humana (Rio de Janeiro: Forense Universitária, 2007) e, mais diretamente, nas obras Eichmann en Jerusalém - un estúdio sobre la banalidade del mal (Barcelona: Editorial Lumen, 2003) e Responsabilidad y juício (Barcelona: Paidós, 1995). 
de possibilidade de que os sujeitos, envoltos em certas circunstâncias percebam, compreendam e deem-lhe resolução satisfatória pessoal e coletiva.

\subsection{A postura docente de Arendt}

Subjaz à perspectiva arendtiana acerca do pensar uma ideia pedagógico-educacional como que a indicar a direção futura de suas reflexôes relacionadas às atividades do espírito. Neste sentido, no dizer de Peiró, Arendt considerava que "sua tarefa como docente era importante em sua forma de entender seu lugar no mundo e entre os outros" (2014, p. 252). A ênfase desta passagem dá conta da existência de uma forma de pensar que intenta desenvolver compreensóes sobre o mundo que abarquem a individualidade em meio à coletividade. A partir desta posição, suas aulas e sua produçáo escrita, embora muitas vezes trouxessem dissabores - vide críticas pós-livro sobre Eichmann -, carregavam em seu interior uma firme decisão à conformação de um espaço de pensamento próprio às pessoas. Emerge desta forma de entender a relação entre educador e educando uma compreensão da função docente como sendo de plena responsabilidade no sentido de dotar as atribuiçóes pedagógicas de um caráter impulsionador para o livre pensar por parte dos estudantes. Isto é, à docência, em sua dimensão formativa integral, reserva-se uma responsabilidade emancipadora, com raízes na concepção de ação humana intencional que visa dotar os educandos da capacidade de pensar por si mesmos. Urge considerar que, em Arendt, o conceito de responsabilidade:

[...] não pode desligar-se de sua aposta por pensar o espaço político como o requisito e o resultado da açáo e a palavra dos plurais (a irredutível singularidade dos sujeitos únicos); não pode ser separada de sua reflexão sobre pensamento e juízo político como formas de profilaxia contra as tentações das ideologias, os automatismos de nossas ações e a banalidade de nossas opiniōes (PEIRÓ, 2014, p. 255).

Resulta desta ideia de responsabilidade a necessidade de atenção pessoal e coletiva no sentido de proteção da pluralidade existencial e do mundo: afinal, é neste que se realiza a ação e a palavra humana, e é neste que germina a semente da experimentação da liberdade. Neste mundo ao qual chegamos e integramos por um espaço de tempo biológico natural, variável e finito, compartilhamos a existência e estamos vinculados em uma mútua responsabilidade. É esta percepção de chegada, permanência espaço-temporal e finitude - que dota o sujeito arendtiano da condição de fragilidade -, o impulso decisivo à mútua responsabilização. O sujeito frágil em Arendt coloca a exigência da presença ativa do outro: há aqui uma noção de coletivo que leva à condição de possibilidade para a assunção da responsabilidade recíproca.

\subsection{As atividades do espirito}

A delimitação teórica a que nos reteremos recai diretamente sobre o conceito de pensar, embora façamos uma breve referência às outras duas dimensôes trabalhadas em $A$ vida do espirito, entendendo com a autora que "Pensar, querer e julgar são as três atividades espirituais básicas. Não podem ser derivadas umas das outras [...] não podem ser reduzidas a um denominador comum" (ARENDT, 1991, p. 55, grifo nosso). Na acepção acima descrita temos o esclarecimento de que, embora características comuns interliguem as três dimensóes básicas do espírito, elas colocam sua efetividade na ordem de algumas peculiaridades. Estas se referem ao caráter de inderivação e irredutibilidade, de incondicionamento - seja pelo sujeito, seja pelo mundo -, quer dizer, 
ocorrem de forma autônoma, obedecendo a leis inerentes à atividade própria de cada uma. São, ainda, de natureza reflexiva, advindo desta a sua condição de invisibilidade, isto é, trata-se de uma atividade interna ao sujeito, imperceptível aos demais. E apontam decisivamente para o dualismo da consciência, uma vez que envolve a atividade reflexiva de um agente que atua sobre si mesmo. Faremos, a seguir, uma livre e breve reconstrução do julgar e do querer, apenas para situá-los em relação ao pensar. Após, exploraremos de forma mais ampla o pensar que, para nós, resulta crucial para as questôes relacionadas ao problema de fundo vinculado à perspectiva de transformação da "promessa" democrática em resoluçôes efetivas às necessidades e às aspiraçôes existenciais dos sujeitos.

\subsection{As dimensóes do julgar e do querer}

O julgar incide sobre objetos particulares, sendo que estes são elementos concernentes ao mundo das aparências e, para a sua adequada realização, coloca a exigência da retirada momentânea do mundo, pressupondo o retorno ao mesmo após a abstração reflexiva. Surgem nesta atividade uma dupla e concomitante dinâmica: na primeira, sai de cena o ator, o sujeito diretamente implicado em uma determinada ação ou contingência. Na segunda, entra em cena o espectador, o sujeito que, em certo sentido, permanece vinculado à ação e à contingência, mas que, distanciado o suficiente, abstêm-se do imediato e do evento em si. Tal distanciamento implica, além da anulação da imediaticidade, a pressuposição de uma retirada deliberada dos envolvimentos e dos interesses particulares. Em resumo, dialogar consigo mesmo depende de quietude em relação às paixôes que movem a alma ${ }^{7}$. Importante ainda, no que tange as relaçôes sociais "O julgamento não se orienta por aquilo que agrada a cada um, mas exige um distanciamento dos interesses próprios e a capacidade de imaginarmos o ponto de vista dos outros" (ALMEIDA, 2011, p. 153).

O querer, assim como o julgar, dá-se em relação a objetos particulares do mundo das aparências e envolve a retirada momentânea destas com o posterior retorno às mesmas. Aparece neste sentido a volição como elemento que impulsiona: a vontade antecipa o que ainda não é dotando-o de uma característica de projeto a realizar, ou seja, o objeto adquire o status de intenção, ou, ainda, "a vontade não se ocupa de objetos, mas de projetos [...] com a futura disponibilidade de um objeto que ela pode ou não desejar no presente” (ARENDT, 1991, p. 60). A perspectiva temporal aqui imbricada é a de futuro, sendo que nesta projeção podem apresentarse complicaçôes subjetivas frente aos diferentes interesses que perpassam a vida cotidiana. Neste sentido, advém da dimensão do querer uma dupla e imprescindível tarefa à dimensão do pensar. Primeiro, refletir e direcionar a tomada de decisão entre a disposição interna do sujeito singular e o entorno social, entre um sujeito e seus pares em interlocução e convivência, entre o eu e o nós. Segundo, cumprir esta função em relação ao sujeito mesmo e às suas idiossincrasias, afinal, não é de uma só necessidade e nem de uma só aspiração que se conforma a existência humana; ao contrário, no que diz respeito ao querer evidencia-se o concurso da multiplicidade e da variedade. Por fim, esta faculdade do querer liga-se a nossa capacidade inerentemente humana de "iniciar algo novo e, portanto, busca a realização de seus projetos no mundo, mesmo que,

7 Arendt entende alma e espírito como sendo distintos entre si e como competidores invisíveis no sentido de atuaçáo legisladora interior dos sujeitos. A alma seria o lugar gerador e pulsional das paixôes, sentimentos e emoçóes, eventos invisíveis e com expressividade própria. O espírito seria o lugar elaborativo dos princípios existenciais e norteadores dos critérios do julgar e condição para o relacionamento consigo mesmo. 
enquanto atividade do espírito, não ocorra neste” (ALMEIDA, 2011, p. 153).

\subsection{A dimensáo do pensar}

Arendt concebe uma organicidade funcional autônoma a cada uma das três dimensóes explicitadas reconhecendo-lhes independência e interligação. Porém, mesmo entendendo ser equivocado definir uma hierarquia às atividades do espírito, afirma ser inegável a existência de uma ordem orgânica e propedêutica às mesmas. Esta "preparação" traz a tona o processo de desensorialização dos objetos, ou seja, proporciona ao espírito a condição de lidar com objetos ausentes que se fazem presentes pela memória e imaginação, como segue:

A imaginação [...] transforma um objeto visível em uma imagem invisível, apta a ser guardada no espírito [...] mas estes só passam a existir quando o espírito ativa e deliberadamente relembra, recorda e seleciona do arquivo da memória o que quer que venha a atrair o seu interesse [...] nessas operaçóes, o espírito aprende a lidar com coisas ausentes e se prepara para "ir mais além", em direção ao entendimento das coisas sempre ausentes, e que náo podem ser lembradas, por que nunca estiveram presentes para a existência sensível (ARENDT, 1991, p. 61).

Da argumentaçáo acima resulta um duplo e progressivo percurso para o desvelamento de objetos. No primeiro, a imaginação permite a representação do objeto visível, tornando-o invisível para posterior reflexáo acerca do mesmo; com o concurso da memória, a atividade espiritual do pensar relembra e seleciona a representação (invisível) à atenção presente, tornando-a visível. Em outros termos, o visível aos sentidos torna-se invisível através da imaginação representativa; a seguir o invisível representado na memória visibiliza-se pela açáa rememorativa implicada à reflexão referente ao mesmo. No segundo, no "ir mais além” acima descrito, a atividade do espírito, "treinada" nesta operação de reversibilidade recíproca entre o visível e o invisível dos objetos disponibilizados aos sentidos, aprende a lidar com o que não se apresenta jamais aos mesmos. Outro entendimento desta dupla operação é explicitado em termos de que "todo pensamento deriva da experiência, mas nenhuma experiência produz significado ou mesmo coerência sem passar pelas operações de imaginação e pensamento" (ARENDT, 1991, p. 68). Somando-se à imaginação e à memória no sentido de contribuir para o desvelamento dos objetos - dados ou não à percepção sensorial -, temos a metáfora, que contempla as dificuldades surgidas quando "a necessidade da razáo transcende os limites de um dado mundo e nos leva ao mar incerto da especulaçáo" (ARENDT, 1991, p. 80). Emerge neste ponto o recurso à analogia, que representa o esforço de identificar similaridades em duas coisas completamente diferentes que possuam determinadas relaçôes internas e possibilitem dizer de modo diferente o mesmo que já se disse antes visando à compreensão do obscuro. Significa deslocar-se da explicação racional direta, por insuficiência de elaboração heurística e utilizar-se de analogias para alcançar tal resolução.

Para encerrar, destacamos pontualmente, na dimensão do pensar, o seu caráter de reflexividade, de pura atividade da consciência, do poder de anular distâncias espaço-temporais e, talvez, a mais significativa particularidade que apresenta - a natural tendência à autodestruição no que diz respeito às suas próprias elaboraçôes. Pensamos que é esta, em última instância, a qualidade determinante da relevância da atividade espiritual do pensar. E isto porque, a partir desta característica, instaura-se uma profilaxia que consideramos vital para a elaboraçáo e para a estruturação de axiologias existenciais. $\mathrm{O}$ resultado desta antecipação profilática póe a exigência - e, mais fundamental ainda, disponibiliza espaço público e privado -, de uma permanente, 
constante, renovada e salutar revisão do pensamento. Um repensar, pois, acerca das necessidades, das aspirações e da normatização das relaçôes entre sujeitos com pretensóes de liberdade consentida a partir de uma subjetividade livre e, ao mesmo tempo, comprometida, não só com o universo particular, mas também com o geral.

\section{Consideraçóes finais}

À perspectiva inicial - refletir acerca das possibilidades contidas em regimes pautados pela democracia a partir de Amartya Sen, e pelas elaboraçôes teórico-filosóficas de Hannah Arendt sobre o pensar -, somam-se agora os desafios inerentes à educação. Pensamos que a elaboração teórica destes dois autores referenda explicitamente uma concepção pedagógico-educacional específica que intentaremos caracterizar, minimamente, nas linhas abaixo.

Sen, de maneira primorosa, demonstra o vínculo entre regimes democráticos e a constituição de espaços para a manifestação pública das necessidades e aspiraçóes dos sujeitos. Em sua visão, à democracia é reservada uma tríplice função a) Ser a mola propulsora da atividade cidadã ancorada na ideia de liberdade política b) Permitir, a partir desta atividade, o caráter de valor instrumental contido na alavancagem de solicitaçóes e de cobranças públicas dos cidadãos e c) Constituir o solo onde germinará a construção social de valores norteadores da convivência social. Em outras palavras, está explicitado o elemento subjacente a estas funções: é preciso, em primeiríssimo plano, perceber a existência das necessidades e aspiraçóes. Na sequência, faz-se mister elaborá-las e expressá-las e, finalmente, é preciso embasá-las com argumentos enraizados axiologicamente. Todo este processo exige o pensar sobre, em caráter de vivência e de antecipação aos eventos, de elaboração em relação a eles e de concretização das resoluçóes que emergem de seu interior. E exige ainda o repensar, permanentemente renovado de acordo com o perfil das contingências de uma sociedade entendida como dinâmica e dotada de mobilidade física e abstrata.

Arendt, por sua vez, ao definir teoricamente as atividades do espírito do julgar, do querer e, em especial para o nosso ensaio, do pensar, apresenta elementos claramente próximos aos de Sen. Ao dotar o pensar das necessárias características de retirada do mundo imediato e dos interesses particulares, e de enfatizar o poder autodestrutivo do pensar - dinâmico por natureza -, coloca igualmente a condição do repensar em pauta. Afinal, do interior da plasticidade social, flexível, movediça e também dotada de dinamismo, brotam, incessantemente, novas necessidades e aspiraçôes.

Justamente neste ponto, próximo aos dois autores, é que encontramos a ponte para, aporéticamente, buscar refletir sobre o universo educacional. Com Sen, adotamos o espaço público fornecido pela liberdade política como paradigma possibilitador do pensar participativo potencializado. Com Arendt, tomamos o exemplo da relação com o julgamento de Eichmann e as suas elaboraçôes filosóficas como também paradigmático para constituir sujeitos livres e singulares ao mesmo tempo comprometidos com a coletividade.

O espaço comum às reflexôes de Sen e de Arendt nos encaminha para uma concepção pedagógico-educacional que seja norteada pelo estatuto da liberdade particular comprometida com o coletivo. A constituição desta passa, inexoravelmente, pelo ideal de desenvolvimento pleno das capacidades humanas; neste sentido, o objetivo primeiro e último de qualquer que seja a ação 
educativa envolve o pensar por si mesmo. O não atendimento desta premissa básica pode manter e até perpetuar uma condição visível em nossos tempos: o alheamento dos sujeitos com relação a eles próprios e aos seus princípios e valores internos e a consequente rendição às demandas exteriores, hoje claramente instrumentais e escravizantes. A secundarização do pressuposto básico de formaçáo humana pautada pela contribuição à autonomia e ao comprometimento social pode ser um dos elementos determinantes à ideia de educação percebida como atividade inútil e à concepção de democracia como algo falacioso.

\section{Referências}

ALMEIDA, Vanessa Sievers de. Pensar e conhecer o mundo. In: ALMEIDA, Vanessa Sievers de. Educação em Hannah Arendt: entre o mundo deserto e o amor ao mundo. São Paulo: Cortez Editora, 2011, páginas 146-187.

ARENDT, Hannah. As atividades espirituais em um mundo de aparências. In: ARENDT, Hannah. A vida do espírito: o pensar, o querer, o julgar. RJ: Relume Dumará, 1991, páginas 53-95.

PEIRÓ, Angela Lorena Fuster. Hannah Arendt: responder ante los otros. In: Filosofia e Educação: Interfaces. São Paulo: Képos, 2014, páginas 248-271.

SEM, Amartya. La democracia como valor universal. In: El valor de la democracia. Barcelona: Ediciones de Intervención Cultural / El Viejo Topo, 2006. 